\title{
Defensa preventiva de la democracia: la posición del Tribunal Europeo de Derechos Humanos ${ }^{1}$ \\ Preventive Defense of the Democracy: The position of the European Court of Human Rights
}

\author{
José IGNACIO SOLAR CAYÓN ${ }^{2}$ \\ solarji@unican.es
}

RESUMEN

Las libertades de expresión y de asociación son esenciales para garantizar la apertura del sistema democrático, pero también pueden ser utilizadas para minar sus fundamentos. Por esta razón, el Consejo de Europa decidió establecer un sistema capaz de defenderse frente a posibles amenazas antidemocráticas. Y este espíritu quedó reflejado en el Convenio Europeo de Derechos Humanos. El Tribunal Europeo de Derechos Humanos, a la hora de evaluar si un determinado programa político puede tomar parte en el proceso democrático, ha establecido una doble exigencia: que los medios utilizados sean pacíficos y que el proyecto político propugnado sea democrático. Por tanto, puede excluirse legítimamente la defensa democrática de un proyecto antidemocrático. En virtud de ello, el Tribunal ha formulado en Refah Partisi v. Turkey una doctrina de la defensa preventiva de la democracia que suscita complejas y delicadas cuestiones.

PALABRAS CLAVES: Tribunal Europeo de Derechos Humanos, libertad de expresión, libertad de asociación, defensa preventiva de la democracia, Refah Partisi v. Turkey.

\section{ABSTRACT}

Freedom of expression and association are essentials to guarantee the opening of the democratic system, but they can also be exercised to undermine its foundations. For this reason, the Council of Europe was determined to establish a system capable of defending itself from the antidemocratic threats. And this spirit is reflected in the European Convention on Human Rights. The European Court of Human Rights, when evaluating whether a particular political agenda can take part in the democratic process, has established a dual requirement: that the means used to implement it are pacific and that the political project advocated is democratic. Therefore, the democratic defense of an undemocratic project can be legitimately excluded. According to it, the Court has formulated in Refah Partisi v. Turkey a doctrine of preventive defense of democracy that raises complex and sensitive questions.

KEYWORDS: European Court of Human Rights, freedom of expression, freedom of association, preventive defense of democracy, Refah Partisi v. Turkey.

Fecha de recepción: 23/04/2012

Fecha de aceptación: 21/05/2012

1. Este trabajo se enmarca dentro del PROYECTO CONSOLIDER-INGENIO "El tiempo de los derechos", CSD $2008-00007$.

2. Profesor titular de Filosofía del Derecho. Universidad de Cantabria (España). 


\section{Introducción}

\section{Pluralismo, democracia y derechos funda- mentales: el concepto de "sociedad demo- crática"}

El pluralismo, la tolerancia y el espíritu de apertura son, a juicio del Tribunal Europeo de Derechos Humanos (TEDH), los rasgos distintivos del modelo de sociedad democrática que constituye el substrato del Convenio Europeo de Derechos Humanos. La democracia se nutre del libre debate de ideas y de la discusión en torno a los diversos proyectos y programas políticos que compiten por la dirección de los asuntos públicos. De ahí el papel esencial que en el adecuado funcionamiento del sistema democrático desempeñan los partidos políticos, cuyas actividades -en palabras del propio Tribunal- "forman parte de un ejercicio colectivo de la libertad de expresión” ${ }^{3}$. La protección de las opiniones y de la libertad de expresarlas constituye justamente uno de los objetivos de la libertad de reunión y de asociación, especialmente cuando hablamos de partidos políticos actuando en el ámbito del debate público, de manera que en el ejercicio de sus actividades estos pueden invocar el amparo de los artículos 10 (libertad de expresión) y 11 (libertad de reunión y de asociación) del Convenio. Artículos estrechamente interrelacionados entre sí y que están dirigidos precisamente a garantizar el pluralismo inherente al concepto de sociedad democrática asumido en dicho instrumento jurídico ${ }^{4}$.

Esta apertura comporta sin embargo la asunción por parte del Estado democrático de ciertos riesgos para su propia autopreservación. La experiencia histórica nos ha demostrado fehacientemente que el ejercicio de los derechos y libertades fundamentales puede ser aprovechado por determinados grupos para socavar las estructuras constitucionales del Estado y los propios cimientos del sistema democrático, incluso hasta llegar a acabar con él. Al amparo de las libertades de expresión y de asociación pueden llegar a prosperar políticamente opciones antidemocráticas. Así las cosas ¿cómo puede el Estado democrático defenderse ante tales amenazas? ¿Cabe cualquier tipo de discurso en el debate público o cualquier tipo de programa político en la competición democrática? La democracia ha de enfrentarse así, en última instancia, a la "paradoja de la libertad": ¿debe aceptarse que la libertad pueda conducir a la destrucción de la libertad?

La cancelación de la segunda vuelta electoral en los comicios argelinos de 1992 y la subsiguiente declaración de un estado de emergencia, como respuesta ante la perspectiva de una holgada mayoría del Frente Islámico de Salvación que le hubiera permitido reformar la Constitución y convertir el país en un Estado islámico, nos

3. United Communist Party of Turkey v. Turkey (1998), párr. 43.

4. Como ha señalado el TEDH en el caso Lingens v. Austria (1986), "la libertad del debate político está en el corazón mismo del concepto de sociedad democrática que impregna todo el Convenio” (párr. 42). 
proporciona un ejemplo dramático de aquella paradoja. En este caso fue el propio ministro argelino de Derechos Humanos quien promovió y justificó la toma efectiva del poder por parte de los militares como una medida legítima encaminada a salvaguardar el régimen de libertades ${ }^{5}$. Justamente para evitar llegar a una situación tan extrema como esta son diversos los Estados democráticos que se han provisto de medidas defensivas o de autoprotección frente a opciones antisistema. Y en el campo del Derecho Internacional se ha generalizado una concepción "sustantiva" de la democracia, entendiendo por tal una democracia que, más allá de constituir un simple procedimiento para la toma de decisiones políticas, incorpora unos contenidos materiales mínimos que no pueden ser cuestionados.

En esencia, el problema no es nuevo ni exclusivo del Estado democrático. Ya Locke, en su Carta sobre la tolerancia, advertía esta paradoja con relación al problema de la libertad religiosa, negando el derecho a ser toleradas aquellas iglesias "que no quieren practicar y enseñar el deber de tolerar a todos los hombres en materia de religión”6. Pero en el sistema democrático este problema adquiere una relevancia especial, en la medida en que el fundamento legitimador del sistema reside, justamente, en la posibilidad que en el seno del mismo tienen los diversos proyectos políticos de concurrir libremente a la escena pública, sometiéndose abiertamente a la evaluación de la voluntad popular. De manera que la protección del sistema democrático mediante la exclusión a priori de determinados programas políticos de la competición democrática solo puede lograrse a costa de la limitación de los propios presupuestos del sistema. Pero, ¿hasta qué punto puede la democracia renunciar a sus postulados fundamentales -aun en aras de su autopreservación- sin pervertir el ideal democrático?, ¿en qué medida o bajo qué condiciones cabe justificar una democracia intolerante? Son los propios fundamentos del sistema democrático los que están en juego en la resolución de este problema. Y, probablemente, de la adecuada respuesta al mismo dependerá en buena medida la capacidad del propio sistema para recabar esa legitimidad que justifica su superioridad ética frente a cualquier otro modelo político y que constituye, en definitiva, la mejor -y quizás la única-garantía de perdurabilidad.

Desde la misma creación del Consejo de Europa, con la experiencia aún sangrante de los estragos causados por los regímenes totalitarios, los Estados miembros de dicha organización se mostraron decididos a instaurar un sistema de libertades capaz de defenderse frente a las amenazas antidemocráticas. Y este espíritu se refleja

5. Ali Haroun explicaba así la situación: “Como ministro de derechos humanos, mi pregunta es: ¿quién debe defender la idea de los derechos humanos? ¿Debo permitir una situación en la que, dentro de uno o dos meses, la gente ya no tendrá derechos? No puedo hacerlo. Hoy hay hombres en Argelia que están asumiendo sus responsabilidades. Y hay una gran parte de la población que se vuelve a sentir segura. Vamos a tomarnos el tiempo necesario para fortalecer las instituciones que conduzcan a este país hacia una democracia real -no permitiendo que bajo el pretexto de la utilización de un procedimiento democrático se acabe matando la democracia”-, Human Rights in Algeria Since the Halt of the Electoral Process, Middle East Watch, February 1992, pág. 5.

6. Locke, J., Carta sobre la tolerancia, trad. de P. Bravo, Madrid, Tecnos, 1991, pág. 56. 
en el Convenio Europeo de Derechos Humanos de 1950. De una manera general en su artículo 17, relativo a la prohibición del abuso del derecho, que establece que "ninguna de las disposiciones del presente Convenio podrá ser interpretada en el sentido de implicar para un Estado, grupo o individuo, un derecho cualquiera a dedicarse a una actividad o a realizar un acto tendente a la destrucción de los derechos o libertades reconocidos en el presente Convenio”. Y de una manera particular en el específico apartado segundo de los artículos 8 a 11, donde se prevé la posibilidad de restringir el ejercicio de las libertades de expresión, de reunión y de asociación cuando tales restricciones "constituyan medidas necesarias en una sociedad democrática” para la persecución de determinados fines estatales legítimos, entre ellos la protección de los derechos y libertades ajenos. Cabe reseñar que, si bien en la mente de los redactores del Convenio el totalitarismo aparecía como el principal enemigo, en el contexto internacional actual las principales amenazas para la democracia parecen provenir hoy de los discursos de tipo racista o xenófobo, de los movimientos o partidos políticos de carácter separatista relacionados con organizaciones terroristas y del auge político del integrismo islámico. Y así se refleja en la propia jurisprudencia del Tribunal.

Aunque en un primer momento este no dudó en aplicar directamente el artículo 17 para hacer frente a los discursos y propuestas políticas que

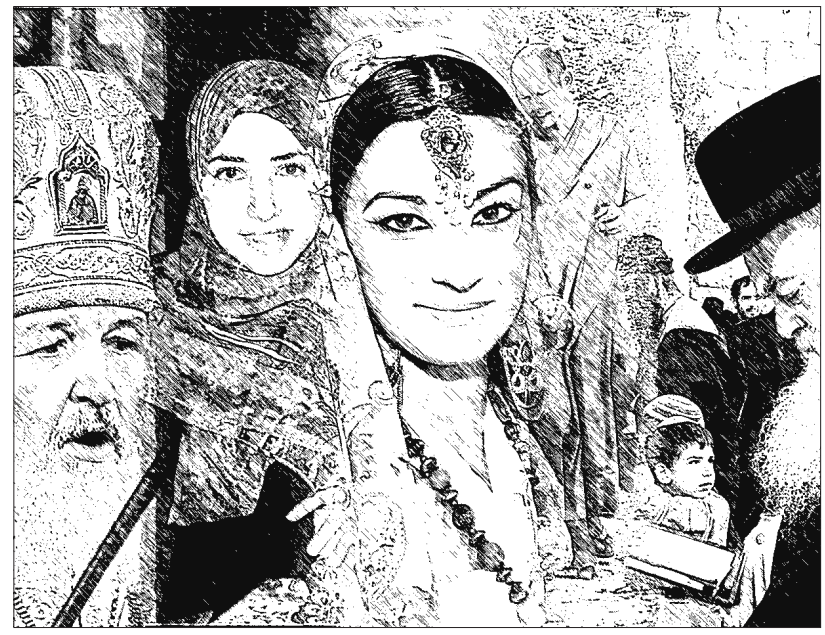

Locke, en su Carta sobre

la tolerancia, advertía esta paradoja con relación al problema de la libertad religiosa, negando el derecho a ser toleradas de aquellas iglesias "que no quieren practicar y enseñar el deber de tolerar a todos los

hombres en materia de religión”.

cuestionaban los fundamentos del Estado democrático, en la actualidad dicho precepto ha pasado a jugar en tales casos un papel subsidiario e integrador -vía interpretativa- de los límites previstos en los diversos derechos concretos, utilizándose como un instrumento para medir la necesidad de la actuación cuestionada en una sociedad democrática ${ }^{7}$.

7. De manera que, como señala Lazcano, I., “Prohibición del abuso del derecho”, en Lagasabaster, I., (dir.), Convenio Europeo de Derechos Humanos, Madrid, Thomson-Civitas, 2004, el artículo 17 no posee hoy un carácter autónomo, puesto que su posible violación ha de estar necesariamente conectada con alguno de los derechos protegidos. Y entonces funciona como "una (importante) regla de interpretación de los derechos del Convenio, más que como una disposición con sustantividad propia” (pág. 578). 
La cláusula "necesario en una sociedad democrática" constituye por tanto el estándar fundamental a través del cual el TEDH desarrolla su tarea de supervisión y control de la actuación estatal en el ámbito de las libertades de expresión y de asociación. De acuerdo con la interpretación que el Tribunal ha hecho de la misma, el ejercicio de estos derechos solo puede ser restringido por las autoridades estatales cuando exista una "necesidad social imperiosa" que justifique la injerencia y cuando esta injerencia sea "proporcional al fin perseguido”. A través del desarrollo jurisprudencial de esta cláusula el Tribunal ha venido a forjar un modelo de orden público europeo en materia de derechos humanos, en el que se revela su concepción sobre el modelo de sociedad democrática inherente al Convenio y la función que en ella ha de corresponder a aquellos derechos.

La noción de "sociedad democrática” viene caracterizada en la jurisprudencia del TEDH como una noción dinámica que es definida tanto teleológicamente, en razón de los fines que dicha sociedad persigue -los ya mencionados de pluralismo, tolerancia y espíritu de apertura-, como instrumentalmente, en cuanto los objetivos políticos únicamente pueden ser alcanzados de forma que se garantice efectivamente el respeto de los derechos y libertades fundamentales ${ }^{8}$. Y, en consonancia con esta doble dimensión, el Tribunal, a la hora de evaluar la compatibilidad de deter- minados discursos o programas políticos con el modelo democrático, ha establecido también una doble exigencia o condición relativa a los medios de actuación y a los objetivos pretendidos:

A. En primer lugar, para que un programa político pueda tomar parte en el proceso democrático es necesario que los medios utilizados para alcanzar sus objetivos sean "legales y democráticos", fórmula mediante la cual el Tribunal alude fundamentalmente a la prohibición de utilizar métodos violentos. El sistema democrático es incompatible con el recurso a la violencia como método de participación política. Por esta razón, se hallan excluidos de la protección del Convenio aquellos discursos que promueven o incitan a la violencia.

Sin duda, uno de los problemas fundamentales en este ámbito es el de la delimitación de la línea fronteriza entre ideas y acción, entre lo que constituye legítimo ejercicio de la libre expresión de opiniones y lo que puede interpretarse como un discurso preparatorio de la actividad violenta. Esto puede llegar a ser en ocasiones muy difícil de determinar. Pero lo cierto es que, como ya advertía Kelsen, el mantenimiento de la democracia, y su propia legitimidad, dependen en buena medida del acierto en esta delimitación ${ }^{9}$. Esta cuestión adquiere hoy una especial relevancia sobre

8. Cfr. GARCía SAn JosÉ, D., Los derechos y libertades fundamentales en la sociedad europea del siglo XXI, Universidad de Sevilla, 2001, pág. 65.

9. Kelsen, H., ¿Qué es justicia?, trad. de A. Calsamiglia, Barcelona, Ariel, 1992: "Es posible que esta línea de demarcación traiga consigo cierto riesgo. Pero el honor y la esencia de la democracia exigen correr este riesgo, y si ésta no puede correrlo, no merece ser defendida” (pág. 62). 
todo en relación con el problema planteado por la existencia de partidos políticos afines a determinados grupos terroristas. De hecho, han sido relativamente frecuentes las ocasiones en las que el Tribunal ha tenido que pronunciarse sobre esta delicada cuestión. Baste citar, por afectar a España, los recursos interpuestos por Herri Batasuna y los subsiguientes partidos políticos herederos de aquel contra las sucesivas decisiones del Tribunal Supremo español que ilegalizaban dichas formaciones. Decisiones ratificadas por el TEDH por considerar que las actividades de estos partidos, por un lado, incitaban a un clima de confrontación social y, por otro, constituían un apoyo implícito al terrorismo de ETA $^{10}$.

B. Pero no basta con respetar el método democrático de toma de decisiones. Es necesario, en segundo lugar, que el proyecto político propugnado (es decir, el objetivo perseguido) sea él mismo de carácter democrático. No cabe pues la defensa democrática de un proyecto político distinto o alternativo a la democracia $^{11}$. El Tribunal se adscribe así a un modelo de "democracia militante", que -como veremos inmediatamente- propiciará una defensa preventiva de la democracia ${ }^{12}$.

\section{Hacia una defensa preventiva de la demo- cracia}

No es necesaria la comisión de actos violentos ni la adopción de un discurso que incite a la utilización de la violencia para excluir un proyecto político de la competición democrática. Basta con que exista la intención de realizar objetivos antidemocráticos una vez que se haya alcanzado el poder democráticamente ${ }^{13}$. Esto supone un

10. Cfr. Herri Batasuna et Batasuna c. Spagne (2009).

11. Posición que, en opinión de KELSEN, H., ¿Qué es justicia?, cit., supone una rendición o abdicación de los propios principios democráticos. A su juicio, “cuando la democracia deja de ser tolerante, deja de ser democracia”. Pero -se pregunta- “puede la democracia ser tolerante en su defensa frente a las tendencias antidemocráticas? Sí, puede en la medida en que no debe suprimir la expresión pacífica de las ideas antidemocráticas". Esta tolerancia es la que "distingue la democracia de la autocracia”. Mientras mantengamos esta diferencia "podremos rechazar la autocracia y sentirnos orgullosos de nuestra forma de gobierno democrática", pero "la democracia no puede defenderse a sí misma si se rinde" (pág. 62).

12. La mayoría de países europeos han optado, sin embargo, en sus ordenamientos internos por un modelo de "democracia abierta", en el que únicamente queda excluido el recurso a medios antidemocráticos. Este es el caso del ordenamiento español, donde -como ha señalado nuestro Tribunal Constitucional- no tiene cabida un modelo de democracia militante porque "falta para ello el presupuesto inexcusable de la existencia de un núcleo normativo inaccesible a los procedimientos de reforma constitucional que, por su intangibilidad misma, pudiera erigirse en parámetro autónomo de corrección jurídica, de manera que la sola pretensión de afectarlo convirtiera en antijurídica la conducta que, sin embargo, se atuviera escrupulosamente a los procedimientos normativos (...) Cualquier proyecto es compatible con la Constitución, siempre y cuando no se defienda a través de una actividad que vulnere los principios democráticos o los derechos fundamentales" (STC 48/2003, de 12 de marzo, fundamento jurídico $7^{\circ}$ ).

13. También existen buenos argumentos teóricos en defensa de esta posición. Como razonan Fox, G. H. y NoLTE, G., "Intolerant Democracies", Harvard International Law Journal, vol. 36, n 1 (Winter 1995), "el derecho de resistencia frente a regímenes anti- 


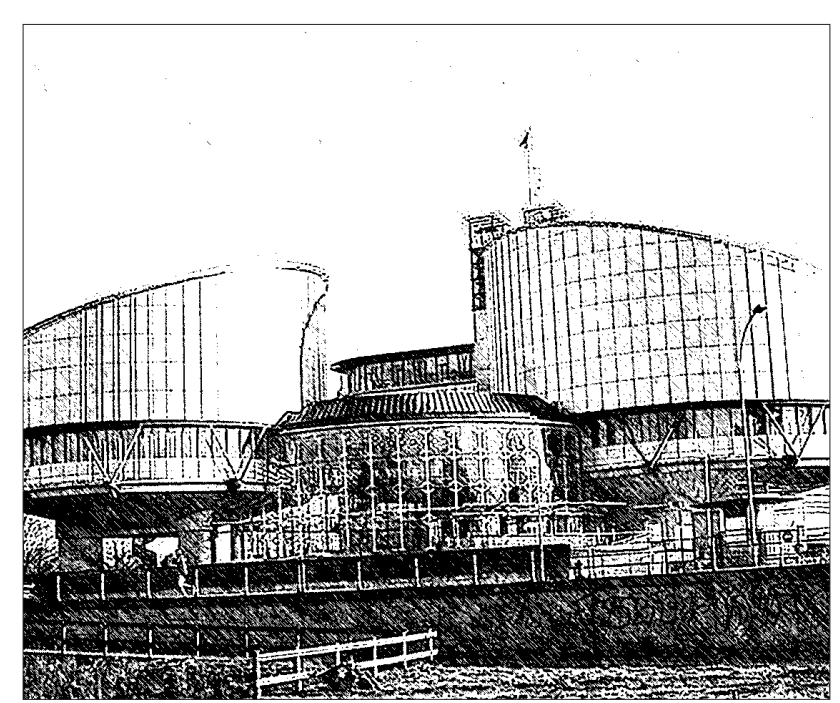

La noción de "sociedad democrática” viene caracterizada en la jurisprudencia del TEDH como una noción dinámica que es definida tanto teleológicamente, en razón de los fines que dicha sociedad persigue -los ya mencionados de pluralismo, tolerancia y espíritu de apertura-, como instrumentalmente, en cuanto los objetivos políticos únicamente pueden ser alcanzados

de forma que se garantice efectivamente el respeto de los derechos y libertades fundamentales. cambio de perspectiva fundamental con respecto a la primera condición, la relativa a los medios. Cuando el juicio se mueve en el ámbito de la utilización de medios antidemocráticos, estamos ante un control a posteriori de determinadas conductas que se estiman peligrosas. Se juzgan actividades que se considera pueden vulnerar las reglas de juego.

Sin embargo, al hablar de la ilegitimidad de los objetivos ya no se trata de enjuiciar hechos acaecidos, sino de anticiparse a las posibles intenciones futuras de un partido político que no se halla comprometido en su actividad política con la violencia ni forma alguna de acción ilegal. Juicio de intenciones antidemocráticas que generalmente resulta difícil de efectuar porque, en este contexto, difícilmente el programa de un partido político se presentará abiertamente como un proyecto liberticida. De ahí que el propio TEDH haya afirmado que "la constitución y el programa de un partido político no pueden ser tenidos en cuenta como el único criterio para determinar sus objetivos e intenciones", siendo necesario que tales contenidos "sean comparados con las acciones de sus líderes y las posiciones que éstos defienden" ${ }^{14}$. Solo mediante la toma en consideración de todos estos elementos podrán inferirse sus intenciones reales. La defensa de la democracia adquiere así en el Convenio un enfoque decididamente preventivo. Es un hecho incuestionable

democráticos está en el corazón de la teoría democrática tradicional”, de manera que, "dada la legitimidad de tales actos, parecería anómalo sostener que los partidos antidemocráticos no pueden ser sujetos a restricciones durante su ascensión al poder, cuando es mucho mayor la posibilidad de derrotarlos". Así, "desde la perspectiva de la moralidad política, lo primero (la resistencia) parecería legitimar lo segundo (las restricciones a los partidos antidemocráticos) a fortiori” (pág. 68).

14. Refah Partisi v. Turkey (2003), párr. 101.

Criterio Jurídico Garantista. AÑo 3, No. 6. Ene.-Jun. de 2012. ISSN: 2145-3381. Fundación Universidad Autónoma de Colombia, Bogotá. 
que en el derecho contemporáneo son cada vez más numerosos aquellos ámbitos en los que el jurista se ve obligado a anticiparse a la realidad, abordando los futuros problemas como riesgos actuales. Una sociedad compleja y altamente tecnificada requiere indudablemente la adopción de una perspectiva preventiva si quiere hacer frente a los desafíos planteados por la protección del medio ambiente, la seguridad del tráfico, el riesgo inherente a las intervenciones médicas, las exigencias de la responsabilidad civil, etc. ${ }^{15}$ Pero este enfoque se ha extendido también a otras zonas del ordenamiento, como la relativa a la protección de los derechos y libertades fundamentales, que suscitan mayores reparos en la medida en que parece difícil conciliar la necesidad de actuar preventivamente implementando determinadas medidas de carácter restrictivo o punitivo con la exigencia democrática de salvaguardar y garantizar aquellos derechos. El reciente desarrollo del denominado "derecho penal del enemigo" -dirigido precisamente contra aquellos que persiguen la destrucción del orden jurídico y que se caracteriza fundamentalmente porque se trata de un derecho que, antes que hechos, "combate peligros"16 - o la cada vez más agresiva defensa preventiva de la democracia tanto en el ámbito del derecho constitucional como del derecho internacional constituyen claros ejemplos de dicha tendencia.

Cabe preguntarse cuáles son esos objetivos antidemocráticos cuya persecución justifica, en opinión del Tribunal, la restricción por parte de los Estados de las libertades de expresión, de reunión y de asociación, hasta el punto de excluir a un partido político de la competición democrática.

En este sentido, una precisión a tener muy en cuenta es que las medidas restrictivas de los derechos y libertades han de estar dirigidas, no a la preservación del Estado en sí, o de su configuración constitucional, sino de la democracia. Es decir, lo que se protege no es un determinado orden territorial, político o constitucional del Estado sino únicamente la apertura del proceso político. El concepto de "sociedad democrática aparece configurado en la jurisprudencia del TEDH como mero "proceso" o "sistema" democrático ${ }^{17}$. La cláusula "necesario en una sociedad democrática", que marca los límites de la intervención estatal

15. Como señala Beck, U., La sociedad del riesgo, trad. de J. Navarro, D. Jiménez y M. R. Borrás, Barcelona, Paidós, 1998, para la supervivencia en la sociedad del riesgo resulta necesaria "la capacidad de anticipar peligros, de soportarlos, de enfrentarse a ellos biográfica y políticamente” (pág. 85).

16. Jakobs, G., "Derecho penal del ciudadano y Derecho penal del enemigo", en Jakobs, G. y Cancio, M., Derecho penal del enemigo, Madrid, Civitas, 2003, pág. 33. Con la configuración de este nuevo modelo, el derecho penal conocería dos polos o tendencias de sus regulaciones. Por un lado estaría el derecho penal "del ciudadano", en el que "se espera hasta que este exterioriza su hecho para reaccionar", y, por otro, el derecho penal previsto para el enemigo, que "es interceptado muy pronto en el estadio previo y al que se le combate por su peligrosidad" (págs. 42-43).

17. Aunque, como señala García RocA, J., “Abuso de los derechos fundamentales y defensa de la democracia”, en García Roca, J. y Santolaya, P. (coord.), La Europa de los Derechos: el Convenio Europeo de Derechos Humanos, Madrid, Centro de Estudios Políticos y Constitucionales, 2005, nunca puede perderse de vista que se trata de "un entendimiento material de la democracia, ligado a derechos y valores, y no solo procedimental o circunscrito a un método para tomar decisiones” (págs. 737-738).

Criterio Jurídico Garantista. Año 3, No. 6. Ene.-Jun. de 2012. ISSN: 2145-3381. Fundación Universidad Autónoma de Colombia, Bogotá. 
legítima, alude así exclusivamente a la protección de dicho sistema. Por ello -afirma el Tribunal- un partido político "no está excluido de la protección otorgada por el Convenio simplemente porque las autoridades nacionales consideren que sus actividades socavan las estructuras constitucionales del Estado" ${ }^{18}$. El hecho de que un determinado proyecto político sea incompatible con los principios y las estructuras constitucionales de un Estado no lo hace contrario a las reglas democráticas. $\mathrm{Al}$ contrario, pertenece a la esencia misma de la democracia el permitir la propuesta y discusión de proyectos políticos diversos, incluso de aquellos que cuestionan el modo de organización actual de un Estado, siempre que se cumplan las condiciones señaladas de respeto al propio sistema democrático (es decir, utilización de medios democráticos y persecución de objetivos democráticos). Por tanto, debe diferenciarse entre lo que constituye propiamente un programa político ilegal -por resultar contrario a los métodos y fines democráticos- y lo que es un programa que legítimamente pretende modificar la legalidad o la propia estructura constitucional del Estado. Nada puede quedar al margen de la discusión democrática, salvo la propia democracia.

El problema en este punto viene dado porque en algunos países europeos la constitucionalidad de los partidos políticos se halla supeditada no solo al respeto del sistema democrático sino también a la aceptación de determinados principios fundamentales de la organización del Estado. Así sucede por ejemplo con el principio de la unidad e integridad territorial del Estado, cuyo reconocimiento constituye en diversos ordenamientos jurídicos una condición sine qua non para la participación política, quedando así sustraído al debate democrático $^{19}$. De hecho, en la mayoría de las ocasiones en las que el Tribunal se ha tenido que pronunciar sobre la legitimidad de la disolución de un partido político por la supuesta incompatibilidad de sus fines con el sistema democrático, la causa de la disolución había sido justamente la defensa de proyectos políticos que cuestionaban la integridad territorial del Estado. Y en todos los casos el Tribunal se ha mostrado firme en su doctrina: las reivindicaciones de autodeterminación de una determinada comunidad, la propuesta de la creación de un Estado federado o incluso la defensa de la secesión y la división territorial del Estado constituyen todos ellos objetivos políticos legítimos en el marco de un sistema democrático. La virtualidad fundamental de este reside en la posibilidad que ofrece de resolver mediante el diálogo, sin necesidad de recurrir a la violencia, los problemas de un país, por muy molestos o irritantes que resulten. Y, bajo este punto de vista,

18. United Communist Party of Turkey v. Turkey (1998), párr. 27.

19. En Francia, por ejemplo, son ilegales todas aquellas asociaciones que atenten contra la forma republicana de gobierno o contra la integridad territorial nacional. Mientras que en el primer caso se ha entendido que el ataque ha de ser violento, en relación con la defensa de la integridad territorial, el Conseil d'Etat ha interpretado que no es necesario que un grupo suponga una amenaza real de acción violenta sino que basta con que cuestione la integridad territorial del Estado. Y de hecho han sido diversos los grupos políticos disueltos en razón de sus objetivos separatistas, aunque ninguno de estos casos ha llegado a verse ante el TEDH. Sí se han presentado sin embargo demandas ante el Tribunal Europeo por parte de partidos políticos disueltos por esta misma razón en países como Bulgaria y Turquía. 
el Tribunal ha reiterado que "una formación política no puede verse inquietada por el solo hecho de querer debatir públicamente la suerte de una parte de la población de un Estado y tomar parte en la vida política de la nación para encontrar, conforme a las reglas democráticas, soluciones que puedan satisfacer a los interesados" ${ }^{20}$.

Y lo mismo puede decirse en relación con la existencia de otras cláusulas constitucionales de intangibilidad, en la medida en que sus exigencias excedan los requerimientos propios del proceso o sistema democrático. Así sucedió en Freedom and Democracy Party contra Turquía (1999). En este caso el partido recurrente había sido disuelto por el Tribunal constitucional turco, entre otras razones, por vulnerar el principio constitucional de laicidad al proponer en su programa político la abolición del Departamento de Asuntos Religiosos. Este organismo es el que administra los asuntos religiosos en el peculiar régimen de laicidad turco (dirige la educación religiosa musulmana obligatoria a lo largo de toda la educación primaria y secundaria, controla y distribuye los sermones que se leen los viernes en las mezquitas, contrata y paga a los imanes, etc.). El partido disuelto por las autoridades turcas propugnaba que estos asuntos estuvieran bajo el control de las propias instituciones religiosas ${ }^{21}$. Y la disolución no fue respaldada por el TEDH al entender que dicha propuesta, aunque claramente incompatible con las estructuras constitucionales y el modelo de organización actual del Estado turco, no infringía sin embargo los principios democráticos ${ }^{22}$.

Solo en uno de los casos planteados ante el Tribunal -también con Turquía como protagonista y con el problema de la laicidad como telón de fondo- aquel ha ratificado la disolución de un partido político por considerar que sus objetivos eran incompatibles con el sistema democrático. Me refiero al notorio y polémico caso Refah Partisi contra Turquía, objeto primero de una decisión sumamente dividida - cuatro votos contra tres-de la Sección $3^{\mathrm{a}}$ del Tribunal, en 2001, y posteriormente de una decisión unánime por parte de la Gran Cámara en 2003.

\section{El caso Refah Partisi: Islam y democracia}

Refah era un partido de ideología islamista moderada, de amplia implantación en el país (tenía más de cuatro millones de afiliados), que, desde

20. United Communist Party of Turkey v. Turkey (1998), párr. 57. Conclusión que el TEDH ha reafirmado posteriormente de manera reiterada en Socialist Party v. Turkey (1998), Razar v. Turkey (2002), Sadak v. Turkey (2002), DEP v. Turkey (2002), Emek Partisi v. Turkey (2005), Parti de la Démocratie et de l'Évolution v. Turkey (2005), The United Macedonian Organisation Ilinden-Pirin v. Bulgary (2006) y Demokratic Kitle Partisi v. Turkey (2007).

21. El Departamento de Asuntos Religiosos constituye el organismo gubernamental que administra los asuntos religiosos en el peculiar régimen de laicidad turco. Como pone de manifiesto el informe sobre ese país realizado por el Relator Especial de la Comisión de Naciones Unidas para la eliminación de todas las formas de intolerancia y discriminación por razones de religión, del año 2000, dicho Departamento - entre otras cosas- es el responsable de la administración de los asuntos internos del Islam, dirige la educación religiosa musulmana obligatoria a lo largo de toda la educación primaria y secundaria, controla y distribuye los sermones que se leen los viernes en las mezquitas, y contrata y paga a los imanes.

22. Cfr. Freedom and Democracy Party (ÖZDEP) v. Turkey (1999), párr. 41. 
su fundación en 1983, había estado participando normalmente en la vida política turca, ajustándose en todo momento sus actividades a la legalidad y a los métodos y las reglas del sistema democrático. Incluso, en el momento de su disolución por el Tribunal Constitucional turco lideraba la coalición política que gobernaba el país. Pero, aún así, el Tribunal Europeo ratificó la decisión del Tribunal Constitucional turco al considerar que Refah perseguía dos objetivos incompatibles con la democracia:

- Primero, el establecimiento de una pluralidad de sistemas jurídicos en función de las creencias religiosas de cada individuo. Objetivo incompatible con el modelo de "sociedad democrática" inherente al Convenio porque, primero, supondría suprimir el papel del Estado como garante de los derechos y libertades individuales, y, segundo, vulneraría el principio de no discriminación en el goce de los mismos.

- Segundo, la instauración de la Sharia o ley islámica como derecho común y como derecho aplicable a la comunidad musulmana. En este caso el Tribunal señaló que en dicho régimen no podían tener cabida principios como el pluralismo en la participación política o la evolución incesante de las libertades públicas, enfatizando además su incompatiblidad con el sistema democrático en algunos aspectos concretos como el relativo a las garantías penales y procesales o al estatus jurídico de la mujer ${ }^{23}$.

Difícilmente puede cuestionarse la incompatibilidad de tales objetivos con el sistema democrático. Y por ello el TEDH consideró la disolución de Refah como el legítimo ejercicio por parte de Turquía de un poder de intervención preventiva en defensa de la democracia. Ejercicio que justificaba en razón de la existencia de un peligro "suficientemente probado e inminente" 24 . Precisión interesante, y muy a tener en cuenta, porque parece que viene a establecer la exigencia de un timing adecuado para la disolución, apelando a una fórmula que nos trae a la memoria el estándar del "clear and present danger" tradicionalmente utilizado por el Tribunal Supremo estadounidense. Como el Tribunal Europeo ya había dejado entrever en su argumentación en los casos Yazar contra Turquía y DEP contra Turquía, cuando se aborda el problema de la compatibilidad de los objetivos de los partidos políticos con los principios democráticos, no basta solo con mostrar que sus políticas se dirigen a socavar el proceso democrático sino que, además, para que la inervención estatal esté justificada, se exige que verdaderamente exista la posibilidad real de instaurar ese régimen no democrático ${ }^{25}$.

\footnotetext{
23. Cfr. Refah Partisi v. Turkey (2003), párrs. 119 y 123. Un tercer motivo por el que el TEDH consideró justificada la disolución de Refah fue la posibilidad del recurso a la djihad o "guerra santa", pero en este caso ya no nos encontramos en el ámbito de los fines u objetivos sino en el de los medios antidemocráticos (incitación a la utilización de la violencia), que quedan fuera del objeto de este artículo.

24. Ibidem, párr. 102.

25. Cfr. Yazar v. Turkey (2002), párr. 58 y DEP v. Turkey (2002), párr. 55.
} 


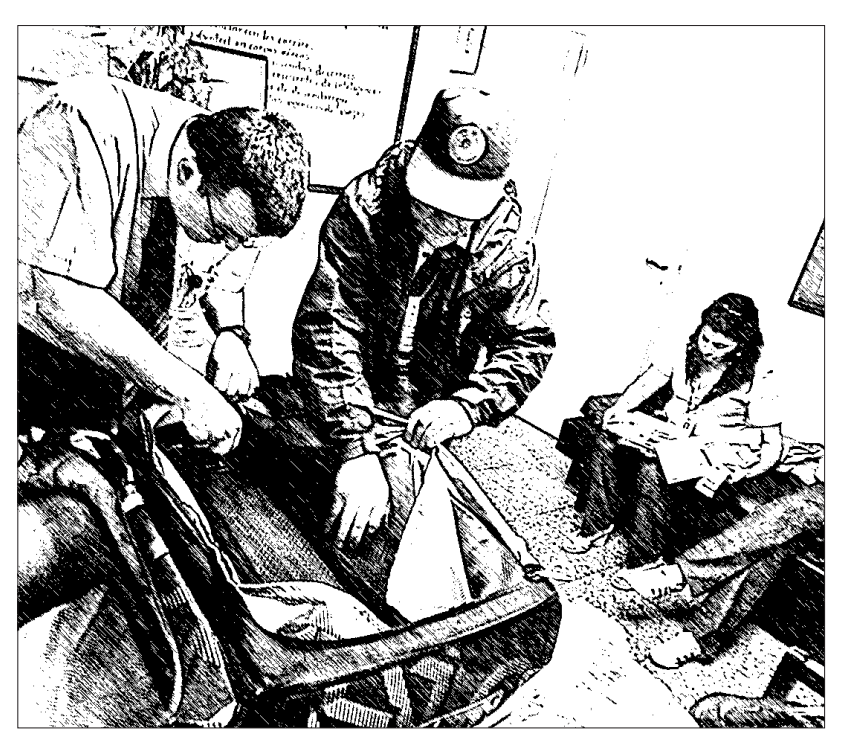

Pero este enfoque se ha extendido también a otras zonas del ordenamiento, como la relativa a la protección de los derechos y libertades fundamentales, que suscitan mayores reparos en la medida en que parece difícil conciliar la necesidad de actuar preventivamente implementando determinadas medidas de carácter restrictivo o punitivo con la exigencia democrática de salvaguardar y garantizar aquellos derechos.

Aún habiendo optado por un modelo de democracia militante, parecen existir sin embargo buenas razones para tolerar a estos partidos en tanto no lleguen a convertirse en una amenaza real para el sistema. En este punto cabe recordar a Rawls, para quien este problema de la tolerancia de los intolerantes está "directamente unido al de la estabilidad de una sociedad bien ordenada". Si la democracia es suficientemente estable y segura, poco se gana excluyéndolos. Al contrario, la libertad de la que disfrutan puede persuadirles a una creencia en la libertad. Esta persuasión se basa en "el principio psicológico de que aquellos cuyas libertades son protegidas y que se benefician por tanto de una Constitución justa, la obedecerán poco después" ${ }^{26}$. En definitiva, se trata de la confianza en la capacidad pedagógica de la democracia. Por otra parte, dicha tolerancia, más que debilitar, puede fortalecer el sistema político. El hecho de que todas las posiciones políticas puedan expresarse libremente en el marco de las instituciones democráticas refuerza sin duda su legitimidad. Incluso, la participación política de los grupos antidemocráticos puede cumplir una importante función en el cuerpo político, funcionando como un mecanismo para la expresión más o menos ordenada del antagonismo básico al sistema ${ }^{27}$. Además, esta visibilidad de los grupos hostiles al sistema se ha defendido también apelando a otras razones de tipo prudencial o pragmático. En este sentido, se ha dicho que la tolerancia de la oposición es un expediente que permite calibrar el grado de insatisfacción con el modelo político, posibilitando que este pueda percibir a tiempo las amenazas latentes. Funcionaría así como una especie de sistema de alarma de la democracia.

\footnotetext{
26. Rawls, J., Teoría de la justicia, trad. de Ma Dolores González, Madrid, FCE, 1993, pág. 253.

27. Cfr. Kirchheimer, O., Justicia política, trad. de R. Quijano, Granada, Comares, 2001, págs. 202-203.
} 
El problema, como señala Rawls, se plantea cuando el grupo antidemocrático es tan fuerte o crece tan rápidamente que las fuerzas del sistema que trabajan en favor de su estabilidad no pueden transformarlo y se acaba convirtiendo en una amenaza real para la democracia. El sistema jurídico debe entonces determinar el momento apropiado para su disolución, anticipándose a la realización efectiva del riesgo. Y se enfrenta aquí a un dilema práctico muy difícil de resolver.

Como se ha señalado, el estándar temporal utilizado por el TEDH para legitimar la disolución es el de la "inminencia” del riesgo. Exigencia que en este caso concreto el Tribunal consideró satisfecha por la privilegiada posición política que ostentaba el partido disuelto, que se encontraba a las puertas de acceder al control exclusivo de los mecanismos gubernamentales de poder. En las elecciones legislativas turcas de 1995 Refah había cosechado el $22 \%$ de los votos, convirtiéndose en el partido con más diputados en la Asamblea Nacional (158 sobre un total de 450). Y este porcentaje de votos se incrementó notablemente en las elecciones municipales de 1996, alcanzando el $35 \%$ de los sufragios. Como consecuencia de tales resultados Refah Partisi accedió al poder en 1996 formando un gobierno de coalición con el "Partido de la Justa Vía”, y su presidente, N. Erbakan, se convirtió en Primer Ministro, cargo que ocupaba cuando el partido fue disuelto en enero de 1998. Además, las encuestas realizadas en aquel momento preveían un porcentaje aún mayor de votos en las siguientes elecciones generales, lo que presagiaba la posibilidad de un futuro gobierno en solitario. Datos todos ellos que -a juicio del Tribunal Europeo- mostraban que, en el momento de su disolución, Refah tenía "el potencial real para apoderarse del poder político sin estar limitado por los compromisos inherentes a una coalición", de manera que "su monopolio del poder le permitiría establecer su modelo de sociedad”. En definitiva, concluye el Tribunal, si los objetivos políticos de Refah constituían en sí mismos un peligro para los derechos y libertades protegidos por el Convenio, la posibilidad real de implementarlos que suponía su previsible acceso en solitario al poder "hacía ese peligro más tangible y más inmediato”. Era, pues, el momento adecuado para la disolución: ni podía criticarse a las autoridades turcas el haber actuado prematuramente, ni se les podía exigir que esperasen hasta que Refah empezara a materializar legislativamente sus planes ${ }^{28}$.

Hasta aquí, la argumentación del Tribunal parece sólida. Sin embargo, el talón de Aquiles de la sentencia se encuentra, en mi opinión, en el problema de la prueba. Es en este punto donde verdaderamente quedan de manifiesto las dificultades existentes para articular jurídicamente una defensa preventiva de la democracia. Especialmente cuando -como ocurre en este caso- el juicio sobre la incompatibilidad de los objetivos del partido con el sistema democrático y, en consecuencia, la decisión de disolverlo, no se funda en el análisis de sus estatutos o de su programa político, ni tampoco siquiera de su actividad política, sino únicamente en determinadas actuaciones y actitudes de algunos de sus integrantes.

28. Cfr. Refah Partisi v. Turkey (2003), párrs. 108 y 110. 
A este respecto cabe señalar que, como reconocían las autoridades turcas, la constitución y el programa político de Refah se ajustaban perfectamente al ordenamiento constitucional del país. No solo eso: Refah era un partido con una larga trayectoria que desde hacía tiempo tenía responsabilidades de gobierno a nivel local. Y, como se ha señalado, en el momento de su disolución llevaba incluso año y medio al frente de la coalición que gobernaba en el país. Período durante el cual no había adoptado ninguna iniciativa ni había llevado a cabo actuación alguna que revelara una intención de perseguir los objetivos políticos anteriormente señalados. De hecho, el programa del gobierno de coalición definía expresamente la República turca como un Estado democrático y laico, y no contemplaba la posibilidad de una modificación del régimen político, y mucho menos la ruptura del orden constitucional. Asimismo, tampoco existía ningún documento del partido, ya fuera público o interno, en el que se hiciera referencia a aquellos objetivos antidemocráticos. De manera que la imputación al partido de los mismos se fundaba exclusivamente en las siguientes declaraciones y actuaciones realizadas por algunos de sus miembros:

a) Dos discursos de su presidente, N. Erbakan, de 1993 y 1995, en los que se pronunciaba a favor de permitir el uso del velo en los establecimientos educativos.

b) La recepción ofrecida por Erbakan en la residencia del Primer Ministro a los líderes de varios movimientos religiosos, que asistieron al evento vistiendo prendas que denotaban su condición religiosa.

c) La aprobación, en 1997, de un decreto gubernamental que reorganizaba los horarios laborales en los establecimientos públicos para facilitar la realización del ayuno durante el Ramadán. Decreto que fue aprobado por el gobierno en pleno -incluyendo los ministros que no pertenecían a Refah- y que contenía medidas muy similares a las que se venían tomando en el país desde 1981.

d) La visita realizada por el ministro de Justicia (vicepresidente de Refah) a un preso que se hallaba pendiente de juicio bajo la acusación de haber realizado actividades contrarias al principio de laicidad.

e) Un discurso de Erbakan, de 1993, en el que defendía la posibilidad de que, bajo unos principios generales comunes, el individuo pudiera regirse en determinados ámbitos del derecho privado (por ejemplo, la forma del matrimonio) por los códigos de su propia religión.

f) Las siguientes declaraciones de tres diputados de Refah en los que se defendía expresamente la instauración de la Sharia o ley islámica:

- Dos discursos de un parlamentario, en abril de 1994, llamando a la introducción de la Sharia. Por ese motivo se abrió un proceso penal contra él. Fue expulsado del partido un mes después de que comenzara el proceso de disolución.

- Un discurso público de 1993 y una entrevista de 1992, reeditada en 1996, de otro diputado defendiendo también la instauración de la Sharia. Se abrió un proceso penal contra él una vez comenzado el proceso de disolución y en ese momento fue expulsado del partido. 
- Unas manifestaciones realizadas el 8 de mayo de 1997 por un diputado, en los pasillos del Parlamento, en favor del establecimiento de la Sharia y en las que amenazaba también con actos de violencia si se clausuraban las escuelas islámicas de teología. Apenas unos días más tarde -21 de mayo- el Fiscal General solicitó la disolución del partido y poco después este diputado fue expulsado del partido.

g) Tres discursos más ambiguos de responsables del partido en los que se hacía referencia al establecimiento de un "orden justo".

Si en el caso de las declaraciones y actuaciones del Presidente y de los vicepresidentes estas podían imputarse directamente al partido, en el caso de los discursos de los tres parlamentarios el TEDH consideraba que la responsabilidad alcanzaba a aquel por no haberse distanciado de estos, al menos no antes de que se solicitara su disolución. La expulsión posterior a dicho momento era interpretada por el Tribunal como un mero intento de escapar a aquella medida. Y, una vez solventado el problema de la imputación al partido de estas actuaciones individuales, el Tribunal concluía que, aunque no todas las actuaciones mencionadas eran ilegítimas en sí mismas, sin embargo "constituían un todo que revelaba los propósitos e intenciones de Refah y, consideradas conjuntamente, proyectaban la imagen del modelo de sociedad que aquel quería implantar" ${ }^{29}$.

Decisión que, como algunos comentaristas han sostenido, tal vez sea cauta y no pueda tacharse de irrazonable. Pero sobre la que se ciernen serias dudas, tal como pusieron de manifiesto los tres magistrados de la Sección Tercera que se opusieron a ella en el primer pronunciamiento del Tribunal. Estos, después de recordar que Refah era -en aquel momento- el decimoquinto partido disuelto por el Tribunal Constitucional turco en un breve lapso de tiempo, resaltaban que la disolución de un partido con base únicamente en comportamientos individuales de sus miembros debía apoyarse en razones muy poderosas y convincentes. Razones que no consideraban satisfechas en este caso porque los actos denunciados eran sucesos aislados acontecidos en contextos muy diferentes a lo largo de un período de casi seis años, y en su mayor parte antes de que Refah llegara al poder. Esta opinión se sostenía -y aquí es donde se encuentra realmente la diferencia con la posición de los cuatro magistrados que conformaron la opinión mayoritaria- en una individualizada y mucho más rigurosa valoración de la prueba. Frente a la valoración conjunta que hacía la mayoría, la minoría procedía a un examen pormenorizado de cada una de las actuaciones y declaraciones.

Desde esta perspectiva, más garantista, resultaba claro que las cuatro primeras (los discursos defendiendo el uso del velo, el decreto reorganizando los horarios laborales para facilitar el ayuno, la recepción ofrecida por el Primer Ministro a distintos líderes religiosos y la visita realizada por un vicepresidente del partido a un correligionario detenido) no planteaban absolutamente ningún problema de compatibilidad con el sistema democrático. Y así lo reconocía incluso la opinión

29. Ibidem, párr. 115. 
mayoritaria, pese a lo cual las tuvo en cuenta por considerarlas relevantes a la hora de trazar una imagen general del proyecto político de Refah, entendiendo que resultaban coherentes con su objetivo inconfesado de establecer la Sharia.

En cuanto a los tres diputados que claramente habían propugnado el establecimiento de este régimen islámico -creo que la única meta que podría considerarse claramente incompatible con el sistema democrático-, la minoría sí consideraba relevante que hubieran sido expulsados del partido, aunque fuera una vez iniciado el proceso de disolución: de hecho, salvo en uno de los casos, tampoco los procedimientos penales contra ellos habían sido abiertos por las autoridades turcas hasta después de iniciado dicho proceso -aunque las declaraciones se remontaban a varios años atrás-, y fue justo en ese momento cuando Refah procedió a su expulsión ${ }^{30}$.

Por lo demás, restaban los discursos, bastante ambiguos, sobre la instauración de un "orden justo", que la mayoría -en el contexto de su apreciación conjunta de los diversos elementos-interpretaba como una llamada a la instauración de un orden político supeditado a los preceptos religiosos, y el discurso de Erbakan sobre la posibilidad de un pluralismo jurídico. En todo caso, declaraciones ambiguas y alejadas en el tiempo que no habían sido objeto de ningún proceso penal o de cualquier otra medida restrictiva -pese a hallar- se entonces vigente el artículo 163 del Código Penal, que sancionaba toda actuación contraria al principio de laicidad-. Y, sobre todo, respecto de las que no había la más mínima prueba que indicase que se trataba de medidas que Refah tuviera efectivamente la intención de implementar.

No cabía, por tanto, a juicio de la minoría, deducir la existencia de una intención o un proyecto antidemocrático del partido como tal. Otra cosa distinta podrían ser las posibles responsabilidades individuales en que pudieran haber incurrido los autores de algunas de dichas actuaciones. Pero en ningún caso una medida tan extrema como la disolución del partido podía considerarse una medida necesaria y proporcionada, ni presentarse como una solución sustitutiva o alternativa al procesamiento de los individuos responsables.

En definitiva, como queda patente en este caso, el juicio sobre la existencia o no de una intención antidemocrática constituye el elemento central sobre el que se sustenta la doctrina del TEDH sobre la defensa preventiva de la democracia. Un juicio que, tal como ponen de manifiesto las dudas arrojadas por la opinión de la minoría en la decisión de la Sección Tercera, no está exento de riesgos. El problema fundamental es la prueba. $\mathrm{Y}$ es que en casos como este ni siquiera puede hablarse de una prueba indirecta o por indicios, puesto que el resultado lesivo de la democracia no llega a consumarse. La realidad es que la decisión

30. A lo que se añadía otra consideración no menos importante: la sección 101 (d) de la Ley de Partidos Políticos (vigente hasta que fue declarada inconstitucional por el Tribunal Constitucional turco apenas una semana antes de que el propio Tribunal disolviese Refah) contemplaba expresamente que si un procesado era expulsado del partido en un plazo de treinta días a partir del comienzo del proceso de disolución, este proceso se cerraría automáticamente. 
en Refah, en última instancia, reposa apenas en un juicio de intenciones o de valor, en una predicción sobre los comportamientos futuros de una asociación; juicio de intenciones sobre el que difícilmente puede proyectarse por tanto el régimen jurídico de garantías previsto para el procedimiento probatorio: ¿cómo puede demostrar el partido cuestionado que no hará ciertas cosas en el futuro? ${ }^{31}$ Se corre así el peligro, ya denunciado por el juez Jackson, del Tribunal Supremo estadounidense, en Denis v. United States de que la decisión judicial se acabe convirtiendo en estos casos en algo no muy diferente a "una profecía en forma de decisión legal”. Profecía sobre cuya fiabilidad, en el caso Refah, el paso del tiempo no ha hecho sino incrementar las dudas. En este sentido, cabe señalar que desde las elecciones generales turcas de 2002 hasta hoy mismo el gobierno turco no ha dejado de estar en manos de un partido islamista heredero de Refah, contando incluso en la actualidad con mayoría absoluta, sin que se haya producido ningún intento de destruir el sistema democrático.

Por otro lado, junto al problema de la prueba se halla el de la apreciación de la existencia del riesgo. Cuestión que resulta de muy difícil objetivación porque, como advierte U. Beck, "los riesgos son reales cuando los seres humanos los viven como reales" ${ }^{22}$. En la sociedad del riesgo la

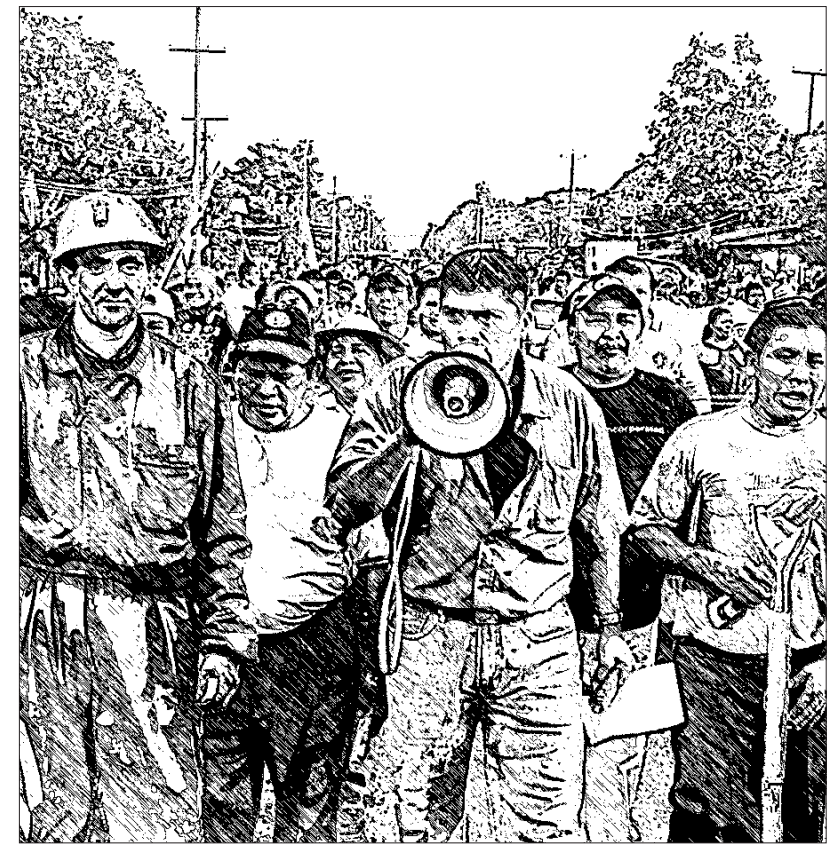

La noción de "sociedad democrática" viene caracterizada en la jurisprudencia del TEDH como una noción dinámica que es definida tanto teleológicamente, en razón de los fines que dicha sociedad persigue -los ya mencionados de pluralismo, tolerancia y espíritu de apertura-, como instrumentalmente, en cuanto los objetivos políticos únicamente pueden ser alcanzados de forma que se garantice efectivamente el respeto de los derechos y libertades fundamentales.

31. En opinión de García RocA, J., "La problemática disolución del Partido de la Prosperidad ante el Tribunal Europeo de Derechos Humanos: Estado constitucional y control de las actuaciones de partidos fundamentalistas”, cit., el resultado al que conduce la opinión de la mayoría es "una presunción con inversión de la carga de la prueba, ya que es el partido quien tiene que acabar por convencer de que no es inconstitucional, porque no hará en el futuro ciertas cosas”. Se le exigiría así "una prueba diabólica” (pág. 324).

32. BECK, U., La sociedad del riesgo, cit., pág. 86. 
mera creencia en una realidad acaba por suplantar a esta, bastando para producir las consecuencias sociales, económicas, políticas e incluso jurídicas correspondientes. Y, de este modo, bajo la presión de los crecientes peligros se forma un material político explosivo. Aquello que hasta ayer era posible, aceptable o asumible, hallándose más allá de las posibilidades de intervención de la política, se transforma hoy en un riesgo inaceptable que debe ser atajado. Esta percepción agudizada del riesgo acaba así trastocando el tejido de competencias, favoreciendo una política dirigista y vigilante que se sirve de la amenaza para ampliar sus posibilidades de intervención ${ }^{33}$. Como resultado de ello, se redefinen responsabilidades, se rebajan las garantías y, en definitiva, se legitiman controles y restricciones otrora difíciles de justificar. En este sentido, resulta constatable cómo en los últimos años, tras los atentados terroristas del 11 de septiembre de 2001, "los fundamentos constitucionales y iusinternacionales se resquebrajan ante el avance de las políticas de la sospecha o de la doctrina de las guerras preventivas" ${ }^{34}$. Es indudable que, bajo la influencia de aquellos acontecimientos y de otros más recientes, la existencia de una percepción social más aguda de la proximidad del riesgo se ha traducido en un incremento paralelo de los niveles de sospecha y de prevención. Y el acentuamiento de esta perspectiva preventiva, que supone la adopción de un enfoque decididamente finalista, ha acabado "contaminando el discurso de lo jurídico, que, como tal, se sitúa lógica y estructuralmente en torno a la cuestión de los medios" ${ }^{35}$.

No cabe descartar incluso que, en relación con el caso que estamos comentando, esta variación en la percepción del riesgo sea precisamente una de las razones que explique la llamativa diferencia existente entre la ajustadísima decisión de la Sección Tercera del TEDH (31 de julio de 2001) y la unanimidad de la sentencia de la Gran Cámara en el año 2003, cuando todos los integrantes del pleno del Tribunal respaldaron sin ambages la disolución de Refah.

\section{Conclusión}

El reciente contexto de la existencia de un nuevo riesgo social ocasionado por las políticas antiterroristas después del 11 de septiembre de 2002, así como la construcción de espacios internacionales para la defensa preventiva de la democracia, pueden alentar la tendencia que parece observarse en algunos Estados europeos de imposición de un permanente estado de vigilancia sobre los partidos políticos. Estado de vigilancia en virtud del cual quedan sujetos a un estricto escrutinio sus resoluciones, documentos, comunicados, el desarrollo de sus actos públicos e incluso las manifestaciones y actuaciones de sus dirigentes y militantes, ya se produzcan públicamente o en el interior de los órganos del partido, en la medida

\footnotetext{
33. Cfr. Ibidem, pág. 87.

34. Asensi, J., "Principales dudas acerca de la Ley de partidos políticos (LO 6/2002 y STC 48/2003)”, en MonTILlA, J. A. (ed.), La prohibición de partidos políticos, Universidad de Almería, 2004, pág. 123.

35. Ibidem, pág. 101.
} 
en que se consideran relevantes para desvelar sus "verdaderas" intenciones.

Una muestra de los problemas que plantea esta asumida exigencia de un control preventivo de los partidos políticos, y de los peligros que supone para el Estado de Derecho, nos la ofrece el procedimiento abierto en Alemania contra el Nationaldemokratische Partei Deutschlands en el mismo año 2003. En este caso, la imputación de objetivos antidemocráticos se basaba fundamentalmente en informaciones obtenidas por los servicios secretos que hacían referencia a declaraciones efectuadas por sus dirigentes en las deliberaciones internas del partido. El procedimiento judicial tuvo que cerrarse al ponerse de manifiesto el importante nivel de infriltración en los órganos de dirección

del partido investigado, de los funcionarios de la Oficina de Defensa de la Constitución que habían suministrado dichas informaciones. Se constató que un tercio de los dirigentes del partido eran agentes gubernamentales, los cuales habían actuado incitando y alentando las posiciones más radicales dentro del mismo. Si la fuerza probatoria de sus informaciones ya era en sí misma discutible, la evidencia de su influencia directa en las actividades del partido las invalidaba completamente, puesto que el origen de la acción que motivaba la sospecha de riesgo para el sistema democrático no podía imputarse ya plenamente al partido ${ }^{36}$.

\section{Bibliografía}

Asensi, J., "Principales dudas acerca de la Ley de partidos políticos (LO 6/2002 y STC 48/2003)", en Montilla, J. A. (ed.), La prohibición de partidos políticos, Universidad de Almería, 2004.

BEck, U., La sociedad del riesgo, trad. de J. Navarro, D. Jiménez y M. R. Borrás, Barcelona, Paidós, 1998.

Fox, G. H. y NolTe, G., "Intolerant Democracies", Harvard International Law Journal, vol. 36, n 1 (Winter 1995).

García Roca, J., "Abuso de los derechos fundamentales y defensa de la democracia”, en García Roca, J. y Santolaya, P. (coord.), La Europa de los Derechos: el Convenio Europeo de Derechos Humanos, Madrid, Centro de Estudios Políticos y Constitucionales, 2005.

GARCía RoCA, J., "La problemática disolución del Partido de la Prosperidad ante el Tribunal Europeo de Derechos Humanos: Estado constitucional y control de las actuaciones de partidos fundamentalistas", Revista Española de Derecho Constitucional, $n^{\circ} 65$ (mayo-agosto 2002).

GARcía SAN José, D., Los derechos y libertades fundamentales en la sociedad europea del siglo XXI, Universidad de Sevilla, 2001.

Jakobs, G., "Derecho penal del ciudadano y De-

36. Cfr. Morlok, M., "La prohibición de partidos políticos en Alemania”, en J. A. Montilla (ed.), La prohibición de partidos políticos, cit., págs. 213-214. 
recho penal del enemigo", en Jakobs, G. y Cancio, M., Derecho penal del enemigo, Madrid, Civitas, 2003.

Kelsen, H., ¿Qué es justicia?, trad. de A. Calsamiglia, Barcelona, Ariel, 1992.

KirchheImer, O., Justicia política, trad. de R. Quijano, Granada, Comares, 2001.

Lazcano, I., "Prohibición del abuso del derecho", en Lagasabaster, I., (dir.), Convenio Europeo de Derechos Humanos, Madrid, Thomson-Civitas, 2004.

LOCKE, J., Carta sobre la tolerancia, trad. de P. Bravo, Madrid, Tecnos, 1991.

MORLOK, M., "La prohibición de partidos políticos en Alemania", en Montilla, J. A. (ed.), $L a$ prohibición de partidos políticos, Universidad de Almería, 2004.

RAwls, J., Teoría de la justicia, trad. de $\mathrm{M}^{\mathrm{a}}$ Dolores González, Madrid, FCE, 1993.
Decisiones del Tribunal Europeo de Derechos Humanos:

- Lingens v. Austria (1986).

- United Communist Party of Turkey v. Turkey (1998).

- Socialist Party v. Turkey (1998).

- Freedom and Democracy Party (ÖZDEP) v. Turkey (1999).

- Yazar v. Turkey (2002).

- Sadak v. Turkey (2002).

- DEP v. Turkey (2002).

- Refah Partisi v. Turkey (2003).

- Emek Partisi v. Turkey (2005).

- Parti de la Démocratie et de l'Évolution v. Turkey (2005).

- The United Macedonian Organisation IlindenPirin v. Bulgary (2006).

- Demokratic Kitle Partisi v. Turkey (2007).

- Herri Batasuna et Batasuna c. Spagne (2009). 